\title{
STRESS INTENSITY FACTOR IN WELDED JOINTS OUT OF DOUBLE ANGLES IN LATTICE STEEL STRUCTURES
}

\author{
Alexander Nikolaevich Shuvalov \\ Moscow State University of Civil Engineering, Moscow, Russian Federation \\ Oleg Vladimirovich Emeliyanov \\ Magnitogorsk State Technical University, Magnitogorsk, Russian Federation \\ Alexander Valeryevich Bultykov \\ Magnitogorsk State Technical University, Magnitogorsk, Russian Federation \\ Milan Prokić \\ Moscow State University of Civil Engineering, Moscow, Russian Federation
}

Steel lattice structures are characterized by presence of zones with constructive stress concentrations and initial technological defects, which usually occur in a result of hand welding. High level of relative loading typical for steel structures, stress concentration and various defects in the weld zones lead to crack initiation. Analysis of building structures failure has shown that from more than 164 steel structure failures that have occurred in 2001-2010, the lattice structures account for more than $64 \%$ of total failures. Earlier performed investigations found that approximately $65 \%$ of the failures are caused by development of cracks from welding defects, $10 \%$ by the initial crack of cyclic origin, $25 \%$ - by high stress concentration. Therefore the design of lattice structures without considering the peculiarities of deformation and fracture of steel in zones of stress concentration leads to increased probability of fatigue and quasibrittle failure.

The present paper investigates behavior of welded joints out of equal angles. Numerical and experimental studies of stress-strain state in the region of crack tip located in the cross section of gusset plate breakage were performed. The functional dependence was obtained that characterizes shape, finite dimensions of element, loading scheme and allows defining the stress intensity factor in the investigated section.

Keywords: Stress intensity factor, Latticed steel structures, Stress-strain state, Crack, J-integral, finite element method.

\section{INTRODUCTION}

Modern methods of structural analysis, using the theory of elasticity and plasticity, structural mechanics, fracture mechanics, allow a high level of reliability in predicting construction behavior under load. Thus it is supposed that the properties of materials and external factors are known. In some cases structural failure is possible due to overload caused by almost uncontrollable natural influences, gross errors in design, operation, or an unfavorable combination of these factors. If we exclude them from consideration, the remaining cases of failure are mostly caused by occurrence and development of macro cracks reaching dangerous or unwanted sizes. Cores of such cracks caused by imperfection of technological processes are contained in the structures prior to their operation. If the crack is not detected in a timely manner, it can lead to an emergency situation.

Elements damage or failure as a result of the crack development is typical form of the limit state in bearing structures of buildings.

The theoretical basis for predicting service life in terms of damage accumulation and development of cracks is the fracture mechanics.

When determining the service life and reliability of metal structures elements using fracture mechanics parameters, the stress intensity factor (SIF), which determines the stress distribution near the crack tip for an elastic body, is required. 
However, the elastic solutions of the crack problem (performed by analytical or numerical method) were obtained only for a limited number of simple geometric forms. For complex configurations of elements the possibilities of analytical methods of determining stress intensity factor are limited.

Currently, there are numerous experimental methods of studying the stress-strain state of material in the region of crack tip: deformed surface etching, method of optically active coatings, Moiré patterns method, interferometry method, photoelasticity method, tensometry methods, etc.

\section{METHODS}

Given the fact, that the obtaining expression for calculating of SIF requires a large number of labor-intensive and expensive tests, in this paper, stress-strain state in investigated section of metal structures was determined by finite element method (FEM). This method mostly meets the requirements of stress-strain state study in the zone of stress concentration, such as: possibility of detail modeling with a given accuracy at any point of the structure; universality (the ability to describe elements of various configurations).

When determining the SIF by finite elements two methods are used - direct and indirect [8, 9]. The first implies that value of SIF is calculated directly by stress distribution in the region of crack tip. In accordance with Irwin solution for the stress state of elastic plate with a crack of length 2 I under stresses $\sigma=\sigma n$, perpendicular to crack, for the case of plane stress state in a generalized form can be written:

$$
\sigma_{i j}=\frac{K_{I}}{\sqrt{2 \pi r}} F_{i j}(\theta)
$$

where $r$ and - polar coordinates with origin at the crack_tip; $\mathrm{KI}$ - stress intensity factor; $\operatorname{Fij}(\theta)$ - trigonometric functions of angle $\theta$;at $\theta=0 \quad \operatorname{Fij}(\theta)=1$.

Thu $\rightarrow$ the definition of $\mathrm{KI}$ is possible when changing stresses in the region of crack tip, as functions of the $\sqrt{ }$.

In the second - SIF is calculated through correlation with other variables: pliability, strain energy release rate or J-integral.

Reference [4] describes implementation of pliability method using the expression for calculat- ing the J-integral

$$
J_{I}=\frac{\Delta z \times P}{\Delta a \times t}
$$

The stress intensity factor can be obtained by formula:

- in case of plane strain

$$
K_{I}=\sqrt{\frac{E}{1-\mu^{2}} J_{I}},
$$

- plane stress state

$$
K_{I}=\sqrt{E J_{I}} \text {, }
$$

Where $E$-modulus of elasticity for steel; $\Delta \mathrm{a}$ - increasment of crack length by small number of nodes without rebuilding the basic finite element mesh; $\Delta z$ - load points displacement difference for the two solutions with increasing crack length by $\Delta \mathrm{a} ; \mathrm{P}$ - load; $\mathrm{t}$ - thickness of the test sample; $\mu$ - Poisson's ratio.

In present paper the determination of SIF was performed for sections of welded joints with elements out of equal angles connected with Tbeam, in the area of gusset plate breakage. This type of connection is one of the basic in designing joints of latticed steel structures, accidents of which make more than $64 \%$ of the total number of steel structures failures [1,3].

Since the distribution of stresses and strains in section depends on the configuration of the joint, computational model in all details reproduces the shape of connection (Fig. 1). A crack in section of gusset plate breakage was modeled with slot width $\delta=0,1 \mathrm{~mm}$.

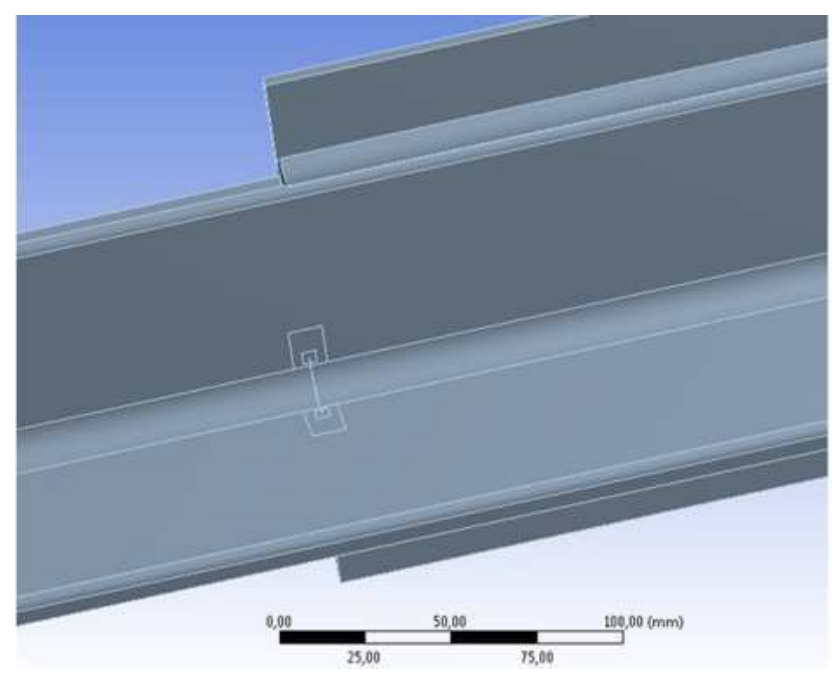

Figure 1: Connection computational model 
In studied connections were varied: relative length of crack $\mathrm{l} / \mathrm{b}=0,15 \div 0,5$; flange width of equal angles: $80,100,125,140,160 \mathrm{~mm}$; flange thickness of angle section: $8,10,12 \mathrm{~mm}$, flange welds from 4 to $8 \mathrm{~mm}$; gusset plate thickness: 8 , $10,12,14,16 \mathrm{~mm}$.

The value of SIF in joints with cracks of various lengths was determined by finite element method in an indirect way - by using the J-integral. The computational model was divided into finite elements of $1 \mathrm{~mm}$ size, except for a region at the crack tip, where rectangular areas were allocated with sizes $15 \times 10 \mathrm{~mm}$ и $4 \times 4 \mathrm{~mm}$, in which the size of finite element was $0.25 \mathrm{~mm}$ and $0.1 \mathrm{~mm}$, respectively. The increasing of crack length $\Delta a$ in calculations was performed by one finite element $-0.1 \mathrm{~mm}$. The calculations were performed by using program complex ANSYS. Fig. 2 shows the distribution of normal stresses in sections, with crack located in the region of gusset plate breakage.

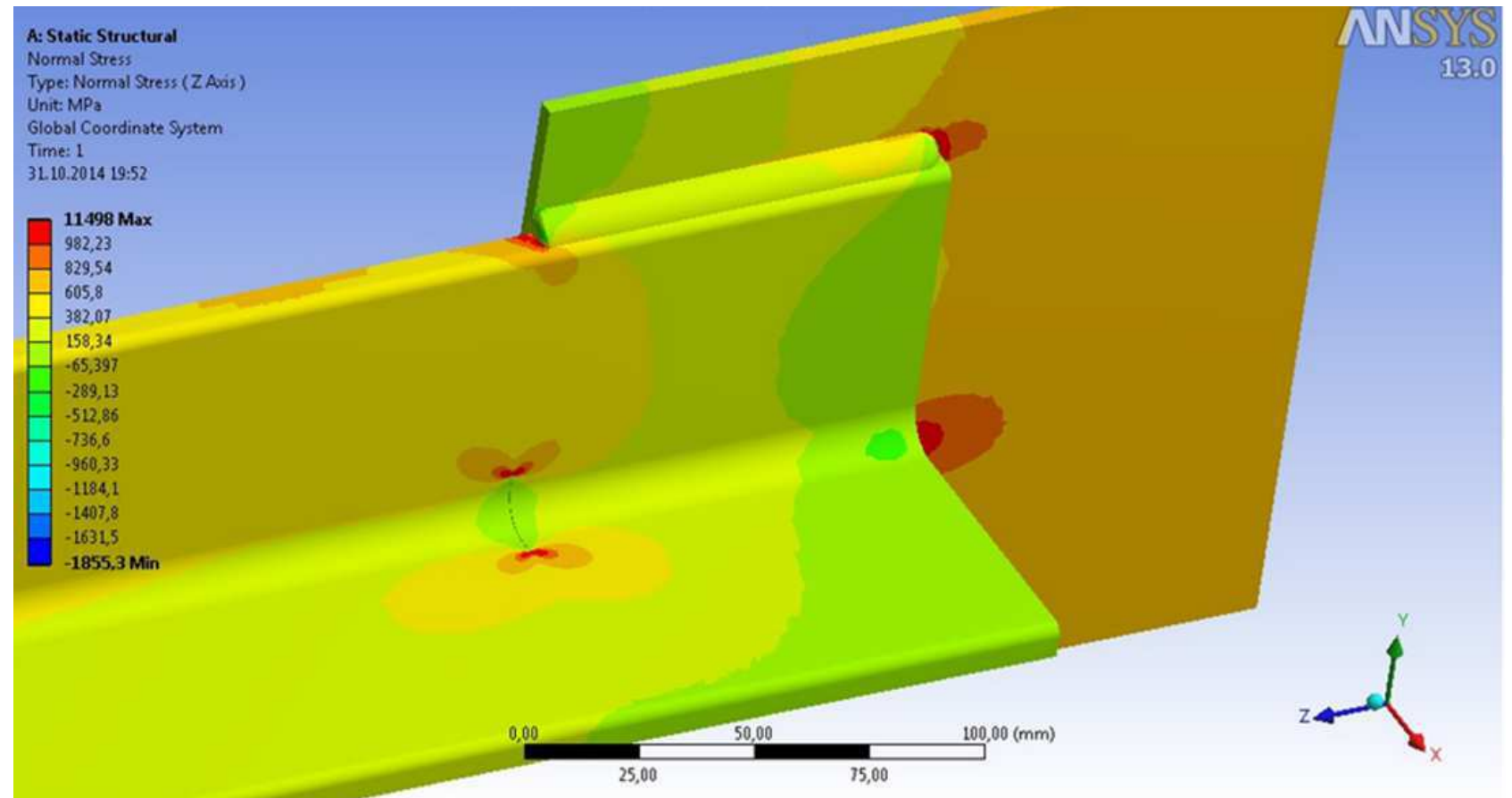

Figure 2: Normal stresses distribution in the studied connection

\section{RESULTS}

A result of calculations values of $\mathrm{JI}$-integral were obtained for different crack length. Figure 3 illustrates variation of $\mathrm{Jl}$-integral depending on the crack relative length $1 / b$, for different values of angles flange width $b$, weld flange kf, weld lengths Iw and with ratio (lk_f) $b^{\wedge} 2 \geq 0,16$.

The expression for calculating SIF in sections of equal angle elements with cracks in region of gusset plate breakage can be written in the following form

$$
K_{I}=\sigma_{\mathrm{H}} \sqrt{l} f_{1 k},
$$

where I - crack length; $\sigma_{-} \mathrm{H}$ - normal stresses in section with crack; $f \_1 \mathrm{k}$ - the functional dependence that characterizes shape, size of the element with crack and loading scheme.

By simultaneously solving equations (4) and (5), $\mathrm{f} \_1 \mathrm{k}$ is given by

$$
f_{1 k}=\sqrt{E J_{I}} / \sigma_{\mathrm{H}} \sqrt{l}
$$

Figure 4 shows variation of $\mathrm{f}_{-} 1 \mathrm{k}$ with relative crack length $\mathrm{l} / \mathrm{b}$. Obtained values $\mathrm{f} \_1 \mathrm{k}$ were approximated by expression

$$
f_{1 k}=0,7436(1 / b)^{2}+0,7837 \mid 1 / b+1,6944(7)
$$

On the same graph values of $f \_1 k$ are marked, obtained during experimental studies of the stress-strain state in the region of crack tip located in cross section of gusset plate breakage in welded joints with equal angle elements. Elements are made from steel 10G2S1 (\lrcorner $\mathrm{L} 70 \times 6)$ and thermostrengthened steel S390 (\lrcorner $\mathrm{L} 80 \times 8)$, by using small base tensometry $[2,10]$. The graph shows that values of $f \_1 k$ obtained by different methods are in good correspondence. 


\section{tegral, $\mathrm{kN} / \mathrm{m}$}

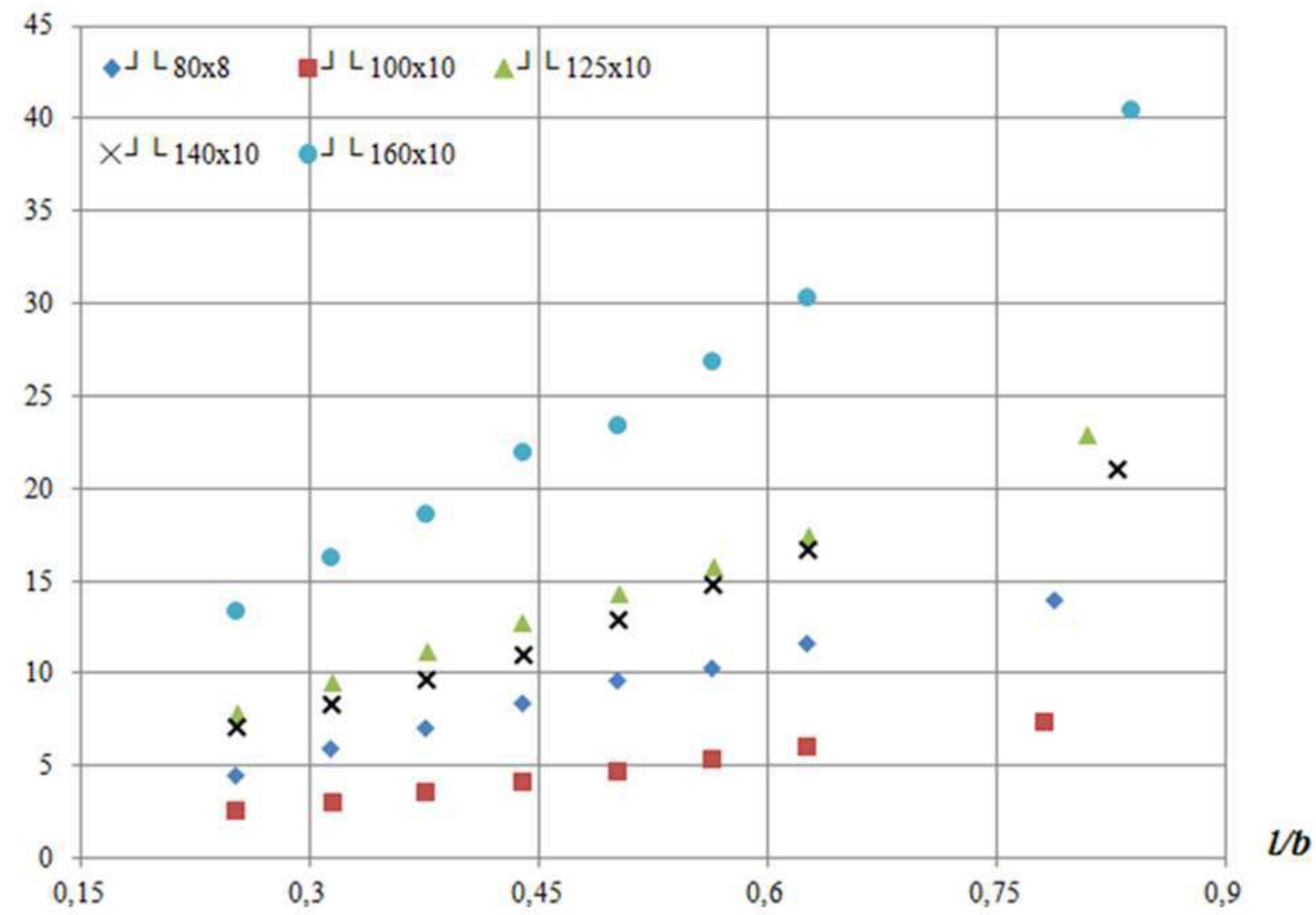

Figure 3: Variation of JI-integral with crack relative length I/b

\section{$f 1 k$}

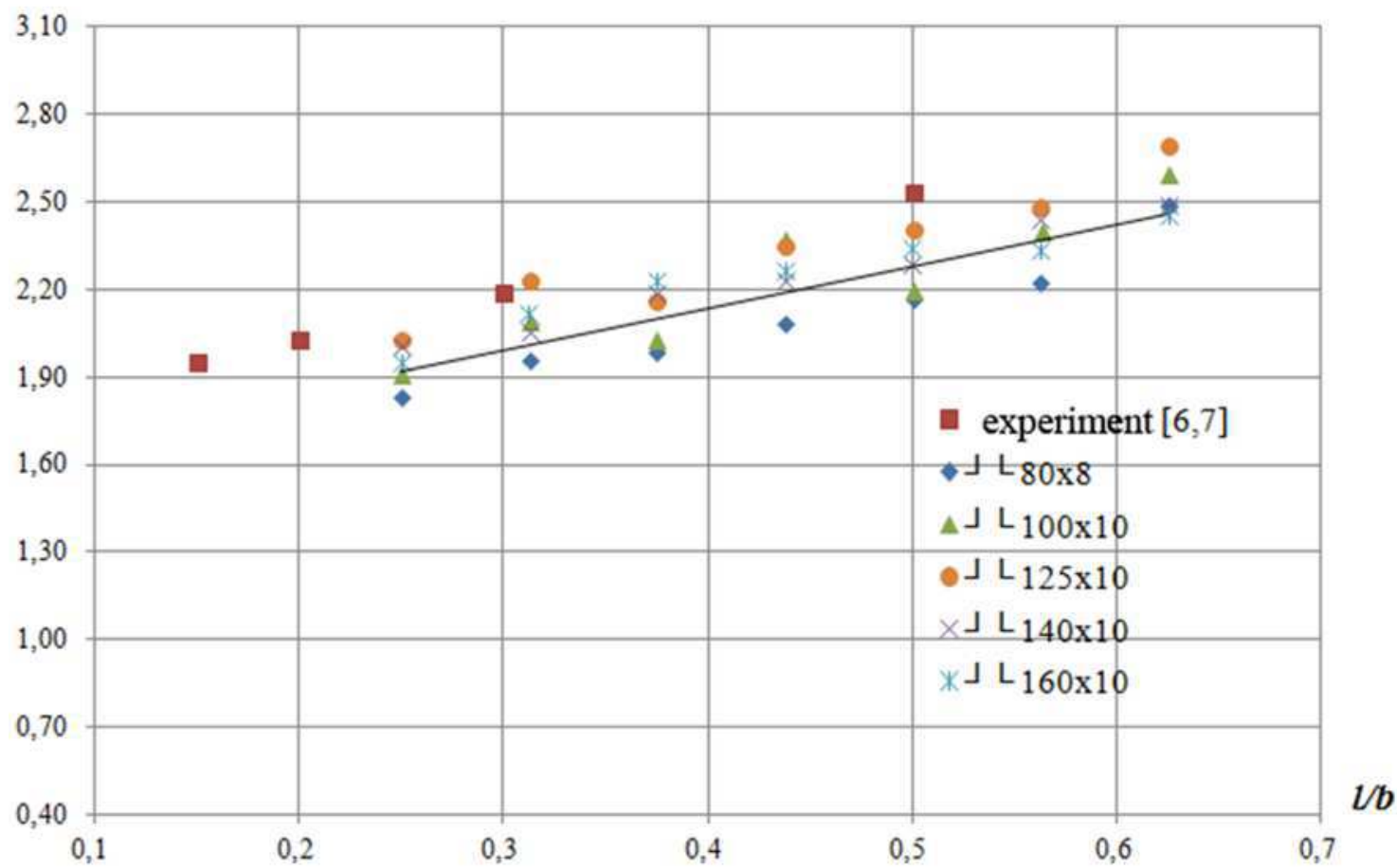

Figure 4: Variation of $f_{-} 1 \mathrm{k}$ with relative crack length $1 / \mathrm{b}$ 


\section{CONCLUSIONS}

Results obtained by numerical studies of crack tip stress-strain state for this type of joints not differ much from previously performed experimental studies. Thus, performed research allow us to recommend proposed expression (7) for determining the functional dependence $f \_1 k$ and stress intensity factor when evaluating service life of welded joints out of equal angles with cracks in the zone of gusset plate breakage.

\section{REFERENCES}

1) Emelianov, O.V., Bultykov, A.V., Shuvalov, A.N. (2012): Influence of Design Parameters of Elements Welded of Double Angles on the Level of Stress Concentration of Connection in the Zone of a Gusset Breakage, Industrial and Civil Engineering, 12, pp. 10-12

2) Emelianov, O. V., Shuvalov, A. N. (2000): Prognozirovanie ostatochnogo resursa tsiklicheski nagruzhaemykh reshetchatykh konstruktsiy, Gradostroitel'stvo, progressivnye stroitel'nye konstruktsii, tekhnologii, sistemy : mezhvuz. sb. nauch. tr. Magnitogorsk : MGTU, pp. 42-52
3) Eremin, K.I., Makhutov, N.A., Pavlova, G.A., Shishkina, N.A. (2011): The register of accidents of buildings and constructions of 2001-2010, Magnitogorsk: Magnitogorsk publishing, $318 \mathrm{p}$.

4) Makhutov, N.A., Koksharov, I.I., Tsyplyuk, A.N. (1991): Determining the characteristics of a stress-strained state for cracks in the zone of a butt-welded joint, Journal of Machinery Manufacture and Reliability, 6, pp. 30-36

5) Maksimović, S., Blažić, M., Maksimović, M. (2010): Design of constructions with respects to fatigue and fracture mechanics, Journal of Applied Engineering Science, Vol. 8, No. 4, pp. 181-188

Paper sent to revision: 10.11.2014.

Paper ready for publication: 27.05.2016. 